\title{
Current predictive controller for high frequency resonant inverter in induction heating
}

\author{
Azzedine Khati ${ }^{1}$, Abdelkader Kansab ${ }^{2}$, Rachid Taleb ${ }^{3}$, Houari Khouidmi ${ }^{4}$ \\ ${ }^{1,2.3}$ Laboratoire Génie Electrique et Energies Renouvelables (LGEER), Chlef, Algeria \\ ${ }^{1,2,3}$ Electrotechnics Department, Hassiba Benbouali University, Chlef, Algeria \\ ${ }^{4}$ Electronics Department, Hassiba Benbouali University, Chlef, Algeria
}

\begin{tabular}{l} 
Article Info \\
\hline Article history: \\
Received Feb 8, 2019 \\
Revised May 5, 2019 \\
Accepted Jul 17, 2019 \\
\hline
\end{tabular}

\section{Keywords:}

High frequency

Induction heating

Inverter

Predictive control

Resonance

\begin{abstract}
In the context of this article, we are particularly interested in the modeling and control of an induction heating system powered by high frequency resonance inverter. The proposed control scheme comprises a current loop and a PLL circuit. This latter is an electronic assembly for slaving the instantaneous phase of output on the instantaneous input phase, and is used to follow the rapid variations of the frequency.To further improve the transient dynamics of the studied system and in order to reduce the impact of measurement noise on the control signal, a generalized predictive control has been proposed to control the current of the inductor. We discussed the main steps of this command, whose it uses a minimization algorithm to obtain an optimal control signals, its advantages are: its design is simple, less complexity and direct manipulation of the control signal. The results have shown the effectiveness of the proposed method, especially in the parameters variation and/or the change of the reference current.
\end{abstract}

Copyright $(0) 2020$ Institute of Advanced Engineering and Science. All rights reserved.

\section{Corresponding Author:}

Azzedine Khati,

Electrotechnics Department,

Hassiba Benbouali University,

B.P 78C, Ouled Fares, Chlef 02180, Algeria.

Email: a.khati@univ-chlef.dz

\section{INTRODUCTION}

In induction heating, the control of current and consequently the power needs more and more of an advanced control technique to ensure a good regulation with precision, quickness and efficiency. Several classical methods of control have been adopted to control the frequency, current and power transmitted into the piece to be heated, whose [1-4] have successively proposed the use of PI and I regulators for induction heating applications.But these conventional control laws may be insufficient because they are not robust, especially when the accuracy requirements and other dynamic features of the system are stringent. An optimal regulator (LQR) has been proposed by [5] and [6], this method is not robust to the uncertainties of the models (uncertainties about the parameters, disturbances ....) [5], and [7] has also proposed the application of sliding mode control in serie-parallel LCC resonators for induction heating.

To have a better control of the coil current and to improve the performance of the controlled system, we propose in this work the technique of generalized predictive control (GPC) [8-12]. The proposed control method uses a minimization algorithm to obtain an optimal control signals. It is simple to design and implement compared to the conventional control method in terms of dynamic response and execution time. The proposed control method has several advantages such as less computational complexity, simpler controller design, direct manipulation of the control signal resulting in variable switching frequency and a faster dynamic response $[8,9]$. 
The main contribution of this paper is the implementation of a high-performance current predictive control law for induction heating application, suitable for controlling a high frequency resonant mode inverters with as objective improve the slaving of the current which depends directly on temperature required for heating. This control strategy is used to develop a GPC control technique based on the prediction of the load current to generate the switching states of the inverter and consequently the supply voltages of the inductor. So, this contribution is a performance evaluation obtained through analyses and simulation.

The paper is organized as follows: firstly, the controlled system inductor-load associate with resonance high frequency inverter selected is modeled. Secondly, we discussed predictive control strategies. Thirdly, the application of the resulting predictive control of induction heating system is provided, of which we have regulated the current of the inductor which is in direct relation with the temperature of the piece to be heated at its desired value. Finally, the numerical simulation of the global system is presented with related results and comments.

\section{PROPOSED RESONANCE HF INVERTER}

The system of induction heating contain essentially: high frequency inverter, one or more inductors, and regulation of power transmitted to the load [13-15]. It is usual to represent induction heating system by electrical circuit equivalent to the inductor-piece to be heated, with equivalent resistor in series or parallel with equivalent inductance [16-20]. Whose: $R_{e q}=R c+R i ; L_{e q}=L c+L i$, With: $R c$, Lc are Load resistor and inductance \& Ri,Li are Inductor resistor and inductance, and: $R_{e q}, L_{e q}$ : equivalent resistor and inductance [19]. In the resonance converters, a capacitor is added to the circuit [21], it is exploited to minimize the electrical constraints on the switches, to maximize the transferred power and to reduce the harmonics [21-25]. Figure 1 shows resonant HF inverter and control stratedjy in IH.

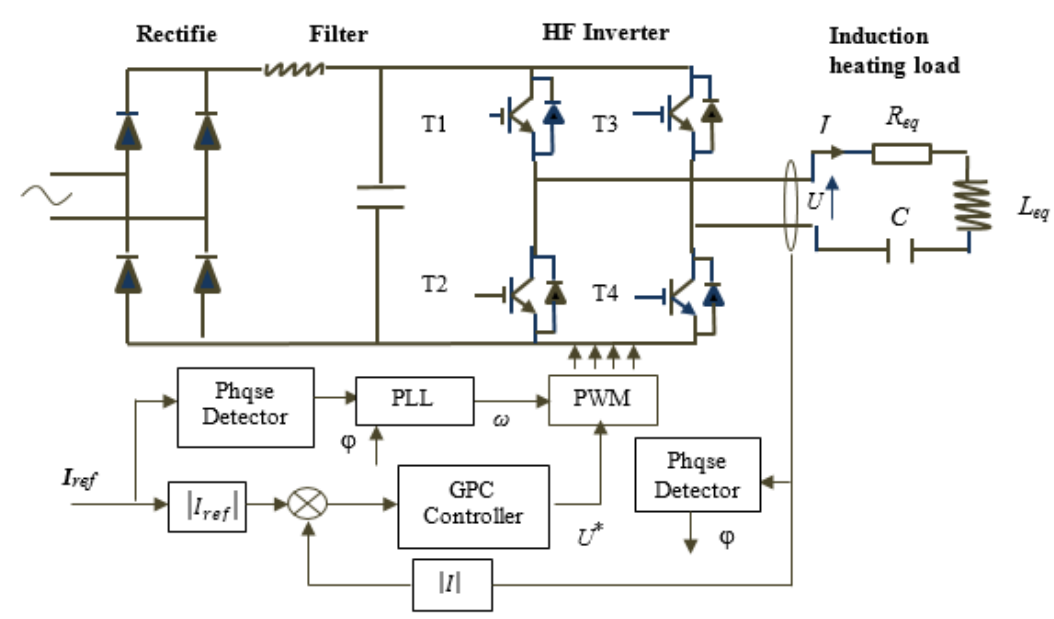

Figure 1. Resonant HF inverter with RLC series-resonant

\subsection{Modeling of the series-resonant inductor-load}

The equivalent equation of the resonant electrical circuit is as follows [20]:

$$
U=\left(R_{e q}+j \omega L_{e q}\right) I+U_{c}
$$

Or by state space [17]:

$$
\dot{x}=A x+B u \quad\left\{\begin{array}{c}
\frac{d I}{d t}=\frac{1}{L_{e q}}\left(U-R_{e q} I-U_{c}\right) \\
\frac{d U_{c}}{d t}=\frac{1}{C} I
\end{array}\right.
$$

whose:

$$
x=\left(\begin{array}{c}
I \\
U_{c}
\end{array}\right), u=(U), A=\left(\begin{array}{cc}
\frac{-R_{e q}}{L_{e q}} & -\frac{1}{L_{e q}} \\
\frac{1}{C} & 0
\end{array}\right), B=\left(\begin{array}{c}
\frac{1}{L_{e q}} \\
0
\end{array}\right)
$$


Capacitor and inductor forms a resonant frequency which can be expressed as [24]:

$$
f=\frac{1}{2 \pi \sqrt{L C}}
$$

\subsection{PWM control strategy for the proposed inverter}

The proposed control strategy consists of two loops: a current regulation loop and a frequency loop (PLL) Phase-locked-loop [26]. The PLL circuit is used to monitor rapid changes of system frequency during the induction heating process, it consists of a current sensor, a zero crossing detector, a low-pass filter and a voltage controlled oscillator (VCO). The VCO delivers a periodic signal whose amplitude is constant and whose frequency is proportional to the DC voltage applied to its input [27].

The current loop is based on the comparison of the output signal of the controller $\mathrm{U}^{*}$ with a variable frequency sawtooth signal. This frequency is generated by the PLL command. The difference between the two signals is applied to the input of a comparator providing a pulse train. In this article, we rely on the synthesis of an advanced current regulator.

\section{CURRENT GENERALIZED PREDICTIVE CONTROL}

The principle of this technique is to use a process model inside the current controller in real time to anticipate the future behavior of the process $[8,9,12]$. The objective of the predictive control strategy is twofold [10]:

a. To estimate the future output of the plant by a linear predictor;

b. To minimize a cost function based on the error between the predicted outputs, the reference trajectory and the future control error increment;

c. At time k, solve an open loop optimal control problem over a predefined horizon and apply the first input;

d. At time $\mathrm{k}+1$ repeat the same procedure. (The previous optimal solution is discarded).

\subsection{Prediction model}

The numerical prediction model is classically defined by the input / output transfer function. In generalized predictive control, the model is represented as CARIMA form (Controlled Auto-Regressive Integrated Moving Average) [11].

$$
A\left(z^{-1}\right) y(k)=B\left(z^{-1}\right) u(k-1)+\frac{C\left(z^{-1}\right) \xi(k)}{\Delta\left(z^{-1}\right)}
$$

With, $A\left(z^{-1}\right)$ : the model input, $B\left(z^{-1}\right)$ : the model output, $\xi(k)$ : white noise centered, $z^{-1}$ : the delay operator, $\Delta\left(z^{-1}\right)=1-z^{-1}$ : ensures integral actin in the corrector, and $A\left(z^{-1}\right), B\left(z^{-1}\right)$ et $C\left(z^{-1}\right)$ : polynomials defined by:

$$
\begin{aligned}
& A\left(z^{-1}\right)=1+a_{1} z^{-1}+\ldots \ldots a_{n a} z^{-n a} \\
& B\left(z^{-1}\right)=b_{0}+b_{1} z^{-1}+\ldots \ldots b_{n b} z^{-n b} \\
& C\left(z^{-1}\right)=1+c_{1} z^{-1}+\ldots \ldots c_{n c} z^{-n c}
\end{aligned}
$$

This CARIMA model is represented by the Figure 2 .

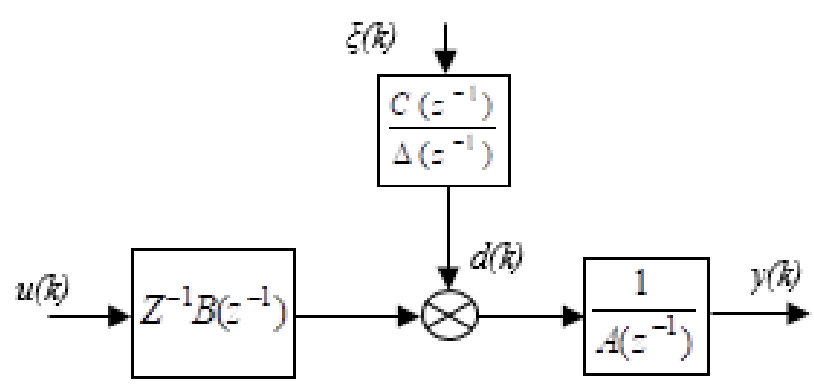

Figure 2. CARIMA prediction model 
The optimal control signal can be achieved with the following algorithm [10]:

The previous iteration, after the minimization procedure at time k-1, gives the control vector:

$$
u=\left[u(k-1), u(k), \ldots, u\left(k+N_{u}-2\right)\right]^{T}
$$

In the first iteration, the input vector control will contain some initial values provided by the user. The number of values presented must be equal to the control horizon.

1. The predictors of orders between $\mathrm{N}_{1}$ and $\mathrm{N}_{2}$ are calculated using the vectors $\mathrm{u}\left(k+N_{l^{-}}-1\right), y\left(k+N_{l^{-}}-1\right)$ and $\mathrm{u}\left(k+N_{2}-1\right), y\left(k+N_{2}-1\right)$.

2. Minimizing the cost function $\mathrm{J}$ with respect to the control vector develops the optimal control signal: $u=\left[u(k), u(k+1), \ldots, u\left(k+N_{u}-1\right)\right]^{T}$

\subsection{Structure of the optimal predictor}

The calculation of $\mathrm{y}(\mathrm{k}+\mathrm{j})$, requires the solution of two Diophantine Fions, based on the model mentioned in (6). The $\mathrm{j}$-step ahead predictor can be taken as follows [11]:

$$
y(k+j / k)=\frac{F_{j}\left(z^{-1}\right)}{C\left(z^{-1}\right)} y(k)+\frac{H_{j}\left(z^{-1}\right)}{C\left(z^{-1}\right)} \Delta u(k-1)+G_{j}\left(z^{-1}\right) \Delta u(k+j-1)
$$

Where: $\Delta T_{e m}(k+j)=0$ for $j \geq N_{u}$

The predicted output $\mathrm{y}(\mathrm{k}+\mathrm{j})$ is decomposed in a conventional manner in free and forced response:

$$
\begin{aligned}
& \frac{F_{j}\left(z^{-1}\right)}{C\left(z^{-1}\right)} y(k)+\frac{H_{j}\left(z^{-1}\right)}{C\left(z^{-1}\right)} \Delta u(k-1): \text { free answer } \\
& G_{j}\left(z^{-1}\right) \Delta u(k+j-1): \text { forced answer }
\end{aligned}
$$

where $F_{j}, G_{j}$ and $H_{j}$ are the unique solution of the following Diophantine equations:

$$
\begin{aligned}
& \Delta\left(z^{-1}\right) A\left(z^{-1}\right) J_{j}\left(z^{-1}\right)+z^{-1} F_{j}\left(z^{-1}\right)=C\left(z^{-1}\right) \\
& \mathrm{C}\left(z^{-1}\right) G_{j}\left(z^{-1}\right)+z^{-1} H_{j}\left(z^{-1}\right)=B\left(z^{-1}\right) J_{j}\left(z^{-1}\right)
\end{aligned}
$$

\subsection{Matrix form of the prediction equation}

To simplify the notations, it is possible to use this matrix representation of the predictor in (5).

$$
\hat{\mathrm{y}}=\mathrm{G} \tilde{\mathrm{u}}+\frac{1}{C\left(z^{-1}\right)} \mathrm{F} y(k)+\frac{1}{C\left(z^{-1}\right)} \mathrm{H} \Delta u(k-1)
$$

with:

$$
\begin{aligned}
& \mathrm{F}=\left[\begin{array}{c}
F_{N_{1}}\left(z^{-1}\right) \\
\vdots \\
F_{N_{2}}\left(z^{-1}\right)
\end{array}\right], \mathrm{H}=\left[\begin{array}{c}
H_{N_{1}}\left(z^{-1}\right) \\
\vdots \\
H_{N_{2}}\left(z^{-1}\right)
\end{array}\right] \text { and } \tilde{\mathrm{u}}=\left[\begin{array}{c}
\Delta u(k) \\
\vdots \\
\Delta u\left(k+N_{u}-1\right)
\end{array}\right], \\
& w_{\text {ref }}=\left[\begin{array}{c}
w_{\text {ref }}\left(k+N_{1}\right) \\
\vdots \\
w_{\text {ref }}\left(k+N_{2}\right)
\end{array}\right], \hat{y}=\left[\begin{array}{c}
\widehat{y}\left(k+N_{1}\right) \\
\vdots \\
\widehat{y}\left(k+N_{2}\right)
\end{array}\right] \text { and } \mathrm{G}=\left[\begin{array}{cccc}
g_{N_{1}}^{N_{1}} & g_{N_{1}-1}^{N_{1}} & \ldots & 0 \\
g_{N_{1}+1}^{N_{1}+1} & g_{N_{1}}^{N_{1}+1} & \ldots & \vdots \\
\vdots & \vdots & \ddots & \vdots \\
g_{N_{2}}^{N_{2}} & g_{N_{2}-1}^{N_{2}} & \ldots & g_{N_{2}-N_{u}+1}^{N_{2}}
\end{array}\right]
\end{aligned}
$$

\subsection{Minimization of the criterion for the elaboration of the control law}

\subsubsection{Cost function}

The GPC control law is obtained by minimizing a finite-horizon quadratic criterion on future errors with a weighting term on the command [10]:

$$
J=\sum_{j=N_{1}}^{N_{2}}\left[\hat{y}(j+1)-w_{r e f}(j+1)\right]^{2}+\lambda \sum_{j=0}^{N_{u}-1}[\Delta u(k+1)]^{2}
$$


where :

$\mathrm{N}_{1} \quad$ : Minimum prediction horizon

$\mathrm{N}_{2} \quad$ : Maximum prediction horizon

$\mathrm{N}_{\mathrm{u}} \quad$ : Control Horizon

$\lambda \quad$ : Weighing factor

$w_{\text {ref }}(\mathrm{k}):$ Reference trajectory

$\hat{y} \quad$ : Predicted output

$\Delta u \quad$ : Increment control signal

With additional conditions: $\Delta \mathrm{u}(\mathrm{k}+\mathrm{i}-1)=0, \quad \mathrm{~N}_{1} \leq \mathrm{N}_{\mathrm{u}}<\mathrm{i}$

The matrix form of the criterion (10) is:

$$
J_{G P C}(\tilde{\mathrm{u}})=\mathrm{M}^{\mathrm{T}} \mathrm{M}+\lambda \tilde{\mathrm{u}}^{\mathrm{T}} \tilde{\mathrm{u}}
$$

with:

$$
\mathrm{M}=\mathrm{G} \tilde{\mathrm{u}}+\frac{1}{C\left(z^{-1}\right)} \mathrm{F} y(k)+\frac{1}{C\left(z^{-1}\right)} \mathrm{H} \Delta u(k-1)-w_{r e f}
$$

The control action (13) is obtained by analytical minimization $\frac{\partial J}{\partial \widetilde{\mathbf{u}}}=0$ of the criterion (11):

$$
\tilde{\mathrm{u}}_{\text {opt }}=-\mathrm{N}\left[\frac{1}{C\left(z^{-1}\right)} \mathrm{F} y(k)+\frac{1}{C\left(z^{-1}\right)} \mathrm{H} \Delta u(k-1)-w_{r e f}\right]
$$

where

$$
\mathrm{N}=\left[\mathrm{G}^{\mathrm{T}} \mathrm{G}+\lambda \mathrm{I}_{N_{u}}\right]^{-1} \mathrm{G}^{\mathrm{T}}=\left[\begin{array}{c}
\mathrm{n}_{1}^{\mathrm{T}} \\
\vdots \\
\mathrm{n}_{N_{u}}^{\mathrm{T}}
\end{array}\right] \text { and } \tilde{\mathrm{u}}_{\text {opt }}=\left[\begin{array}{c}
\Delta u(k)_{\text {opt }} \\
\vdots \\
\Delta u\left(k+N_{u}-1\right)_{o p t}
\end{array}\right]
$$

In generalized predictive control GPC, only the first value of the sequence, the (14) is applied to the system, according to the principle of the receding horizon [9-12]:

$$
u_{\text {opt }}=u_{\text {opt }}(k-1)-\mathrm{n}_{1}^{\mathrm{T}}\left[\frac{1}{C\left(z^{-1}\right)} \mathrm{F} y(k)+\frac{1}{C\left(z^{-1}\right)} \mathrm{H} \Delta u(k-1)-w_{r e f}\right]
$$

\section{SYNTHESIS OF THE PREDICTIVE CONTROL LAW}

The construction of the predictive control laws requires a numerical prediction model of the system, the numerical model used for inductor-load with compensation capacitor according to Table 1 is represented by a continuous transfer function between the voltage $U$ and the current $I$ :

$$
\begin{aligned}
& \text { Table 1. Inductor-load parameters } \\
& T(s)=\frac{I}{U}=\frac{C p}{L_{e q} C p^{2}+R_{e q} C p+1}=\frac{0.42 e-3 p}{10.9 e-7 p^{2}+1.38 e-5 p+1}
\end{aligned}
$$

\begin{tabular}{cccc}
\hline$R_{e q}(\Omega)$ & $L_{e q}(H)$ & $C(F)$ & $f_{c}(H z)$ \\
\hline 0.033 & $25.95 e-6$ & $420 e-6$ & 1525 \\
\hline
\end{tabular}

The discretization of (15) (for one period of sampling of Ts $=10^{-3} \mathrm{sec}$ ) gives the model:

$$
\frac{B\left(z^{-1}\right)}{A\left(z^{-1}\right)}=\frac{-0.2827 z^{-1}+2827 z^{-2}}{1+1.05 z^{-1}+0.2804 z^{-2}}
$$

Where the polynomials $\left(z^{-1}\right), B\left(z^{-1}\right)$ and $C\left(z^{-1}\right)$ in the CARIMA model (4) are:

$$
\left\{\begin{array}{c}
A\left(z^{-1}\right)=1+1.05 z^{-1}+0.2804 z^{-2} \\
B\left(z^{-1}\right)=-0.2827 z^{-1}+2827 z^{-2} \\
C\left(z^{-1}\right)=1
\end{array}\right.
$$


The prediction (9) becomes:

$$
\hat{\mathrm{I}}=\mathrm{G} \widetilde{U}+\mathrm{F} I(k)+\mathrm{H} \Delta \widetilde{U}(k-1)
$$

where:

$$
\hat{I}=\left[\begin{array}{c}
\hat{I}\left(k+N_{1}\right) \\
\vdots \\
\hat{I}\left(k+N_{2}\right)
\end{array}\right], \widetilde{\mathrm{U}}=\left[\begin{array}{c}
\Delta U(k) \\
\vdots \\
\Delta U\left(k+N_{u}-1\right)
\end{array}\right]
$$

With:

$$
F\left(q^{-1}\right)=\left[\begin{array}{c}
F_{1}\left(q^{-1}\right) \\
\vdots \\
\vdots \\
F_{j}\left(q^{-1}\right)
\end{array}\right] ; H\left(q^{-1}\right)=\left[\begin{array}{c}
H_{1}\left(q^{-1}\right) \\
\vdots \\
\vdots \\
H_{j}\left(q^{-1}\right)
\end{array}\right] \text { and } G=\left[\begin{array}{cccc}
g_{1} & 0 & 0 & 0 \\
g_{2} & g_{1} & 0 & 0 \\
\vdots & \cdots & g_{1} & 0 \\
g_{j} & \cdots & g_{2} & g_{1}
\end{array}\right]
$$

The prediction (17) for $\mathrm{j}=1$ is:

$$
\hat{\mathrm{I}}(k+1)=\mathrm{G}_{1}\left(z^{-1}\right) \Delta \widetilde{\mathrm{U}}(k)+\mathrm{F}_{1}\left(z^{-1}\right) I(k)+\mathrm{H}_{1}\left(z^{-1}\right) \Delta U(k-1)
$$

where:

$$
\begin{aligned}
& \mathrm{G}_{1}\left(z^{-1}\right)=g_{1}=-0.2827 \\
& \mathrm{~F}_{1}\left(z^{-1}\right)=-0.0500+0.7696 z^{-1}+0.2804 z^{-2} \\
& \mathrm{H}_{1}\left(z^{-1}\right)=2827
\end{aligned}
$$

The analytic minimization $\frac{\mathrm{dJ}_{\mathrm{GPC}}}{\mathrm{d} \widetilde{\mathrm{U}}}=0$ gives the future control signal (19):

$$
U_{o p t}=U_{o p t}(k-1)-\mathrm{n}_{1}^{\mathrm{T}}\left[\mathrm{F}\left(z^{-1}\right) I(k)+\mathrm{H}\left(z^{-1}\right) \Delta U(k-1)-I_{r e f}\right]
$$

For $\mathrm{N}_{1}=1, \mathrm{~N}_{\mathrm{u}}=3, \mathrm{~N}_{2}=3$ and $\lambda=0.01$ :

$$
\begin{aligned}
& \mathrm{n}_{1}^{\mathrm{T}}=\left[\begin{array}{lll}
-0.0000 & 0.3537 & 0.0000
\end{array}\right] \\
& \mathrm{F}\left(z^{-1}\right)=\left[\begin{array}{ccc}
-0.0500+ & 0.7696 z^{-1}+ & 0.2804 z^{-2} \\
0.7721+ & 0.2419 z^{-1} & -0.0140 z^{-2} \\
0.2033+ & 0.5802 z^{-1}+ & 0.2165 z^{-2}
\end{array}\right] \\
& \mathrm{H}=\left[\begin{array}{c}
2827 \\
-141.3500 \\
2.1827 e+03
\end{array}\right]
\end{aligned}
$$

\section{SIMULATION AND RESULTS}

The inductor-load as shown in Figure 3 with the parameters shown in Table 1, is controlled by the current loop being conceived around the GPC control to generate the switching states of the inverter and consequently the supply voltages of the inductor. Simulations and the tests carried out were focused around this current loop.

\subsection{Discussion}

The choice of settings parameters $\mathrm{N}_{1}=1, \mathrm{~N}_{\mathrm{u}}=1, \mathrm{~N}_{2}=25$ and $\lambda=0.01$, leads to stable and well-cushioned behavior (Figure 4). The sampling period is 0.001 second $\left(\mathrm{k}=10^{-3} \mathrm{~s}\right)$, and we work in an interval of $\mathrm{k}=\left[\begin{array}{ll}0 & 500\end{array}\right]$, which corresponds to $\mathrm{t}=\left[\begin{array}{ll}0 & 0.5 \mathrm{~s}\end{array}\right]$, which confirms the accuracy and speed of 
the trajectory follow-up, with response time equal to $5 \mathrm{k}=0.005 \mathrm{~s}$ without overshoot as shwon in Figure 4 . Carefully modify the control setting parameters as shwon in Figure 5, give us acceptable results with a reduced response time, no overshoot and good reference tracking. For sinusoidal signals as shwon in Figure 6 and Figure 7, the current is superimposed on its reference even with variation of the reference current amptitude.

\subsection{Robustness test}

Figure 8 to Figure 11 respectively show the behavior of the system with its regulation by the predictive control with an increase of the resistance of the inductor-load assembly of $75 \%$ of its nominal value, and decrease of the inductance by $75 \%$ da nominal values at the instant $40 \mathrm{k}=0.04 \mathrm{~s}$. The simulations results show clearly the insensitivity of the predictive control to the variation of the resistance and the inductance. We can notice a little disturbance at the instant 40k, then the current returns to its desired trajectory.

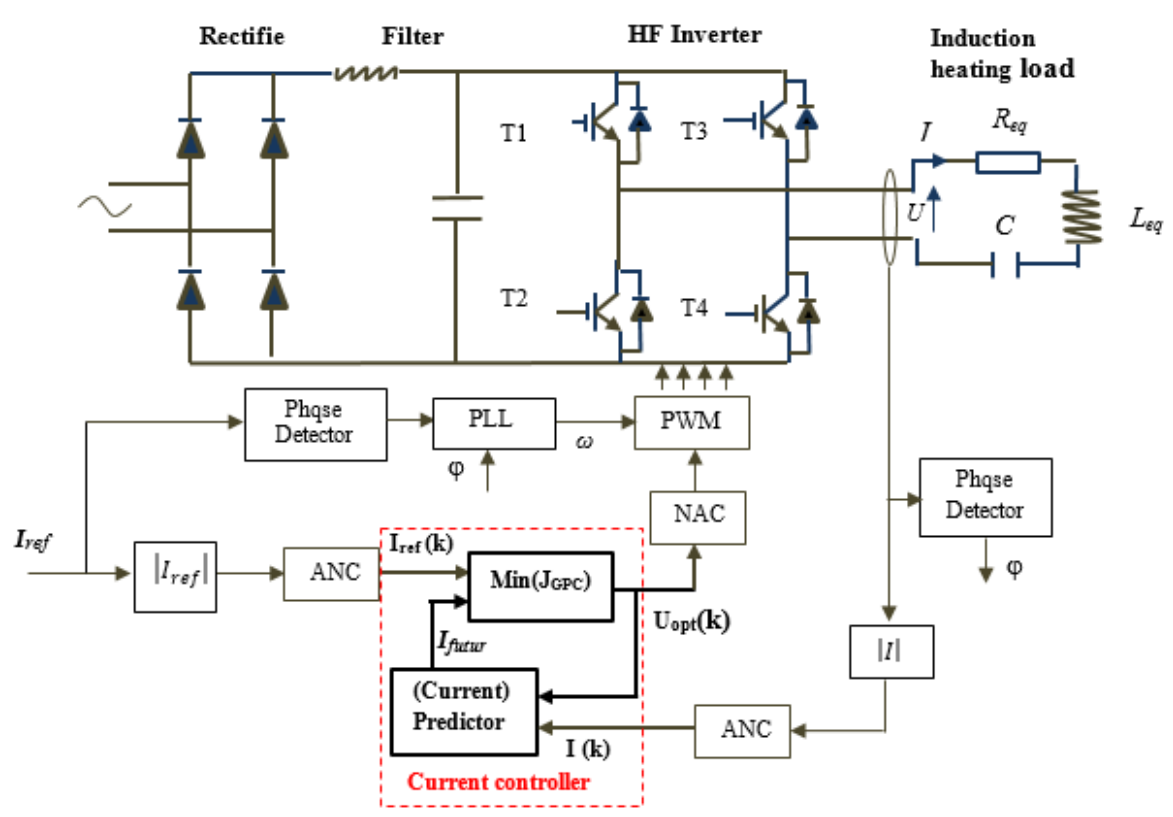

Figure 3. Global Diagram of the induction heating controlled by GPC



Figure 4. Inductor current and its reference

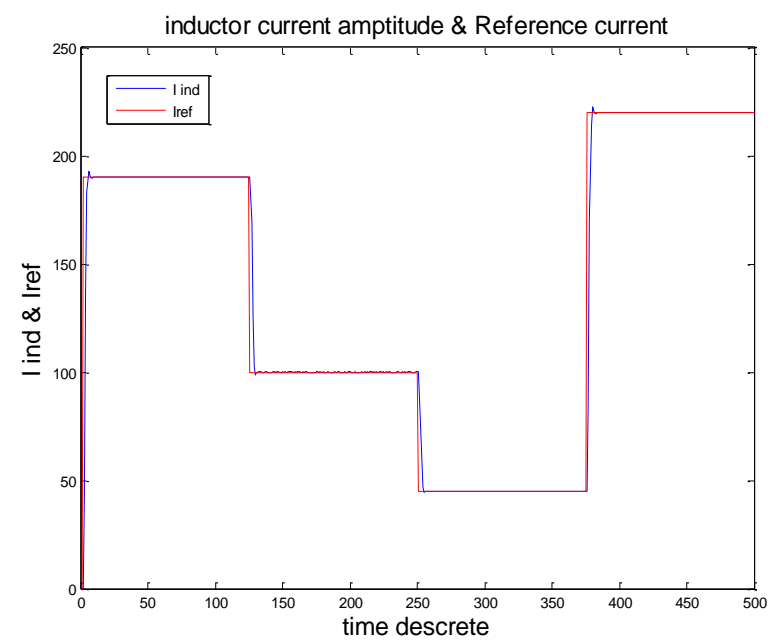

Figure 5. Response for $\mathrm{N} 1=1, \mathrm{~N} 2=27, \mathrm{Nu}=1, \lambda=0.01$ 


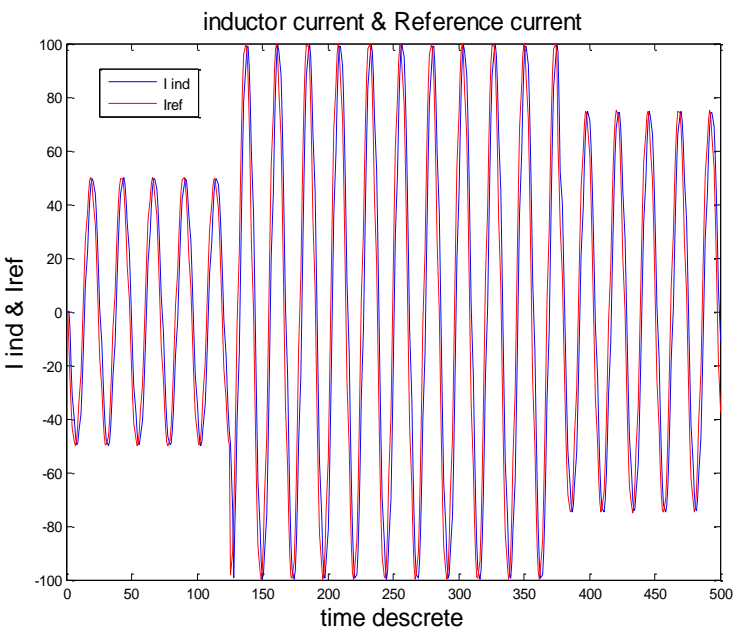

Figure 6. Harmonic response of current in [0 500k]

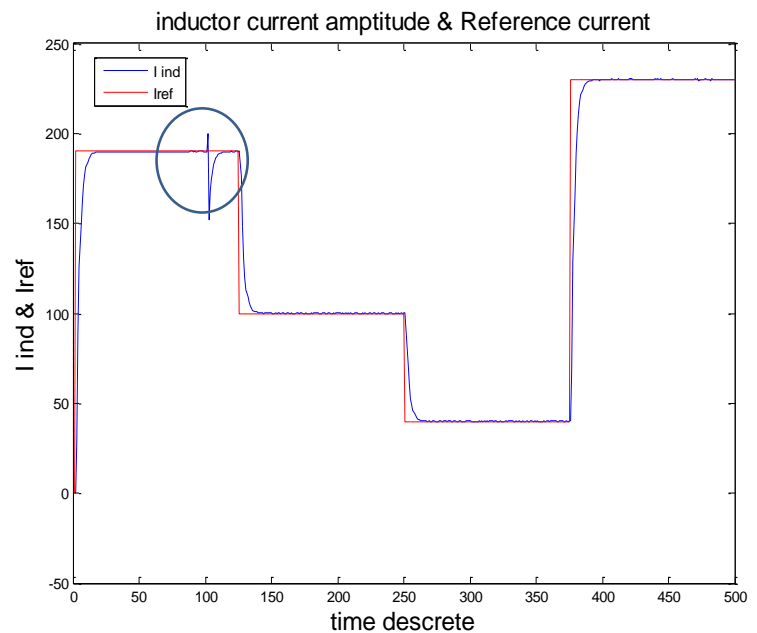

Figure 8 . Robustness test; increasing of $+75 \%$ Req

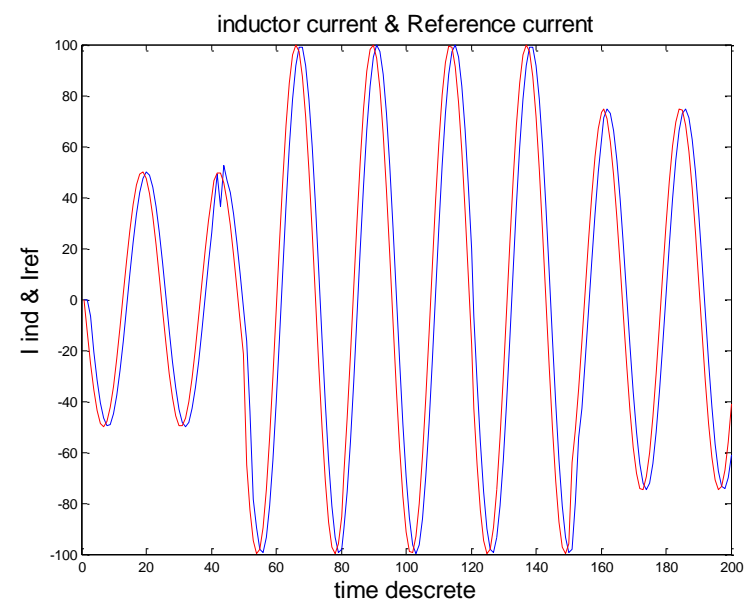

Figure 10. Robustness test; increasing of $+75 \%$ Req

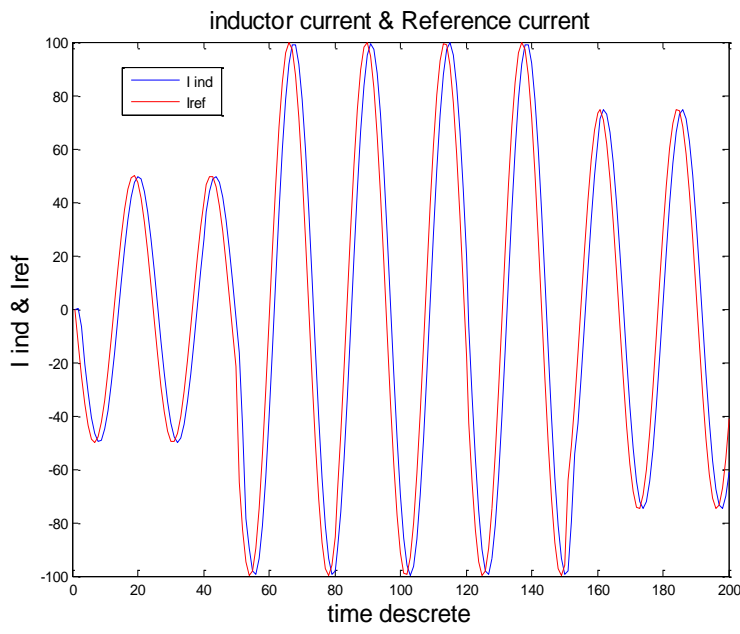

Figure 7. Harmonic response of current in [0 200k]

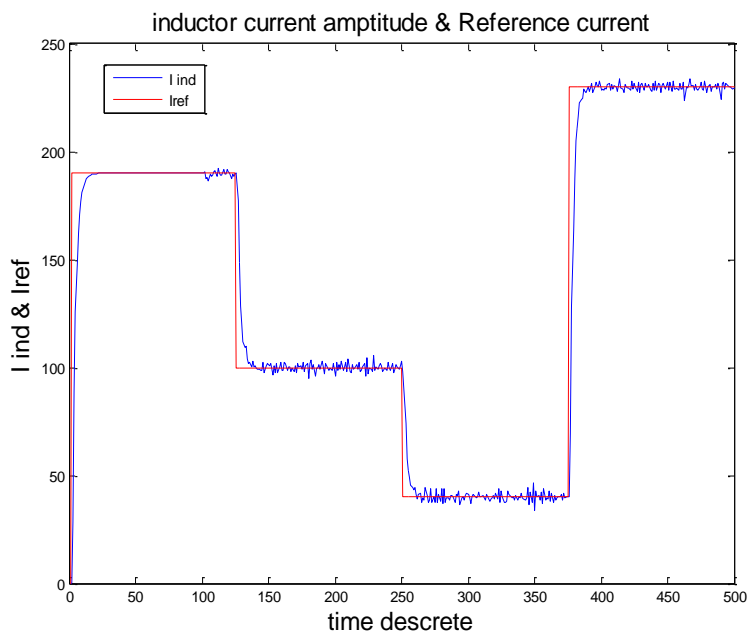

Figure 9. Robustness test; decreasing of $-75 \%$ Leq

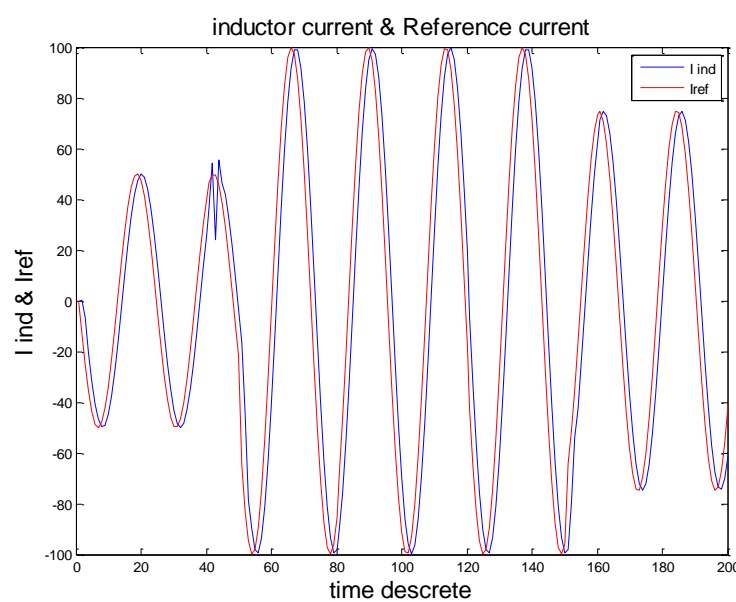

Figure 11. Robustness test; decreasing of $-75 \%$ Leq 


\section{CONCLUSION}

The present work has allowed us to see the modeling and control of high-frequency supply systems (HF inverter) of induction heating, where we have presented the strategy of the predictive control, the central idea and the interest of this articl. All these concepts are detailed in the specific framework of the generalized predictive control (GPC). This method gives very satisfactory results and well during a reference variation than during a presence of disturbance.

\section{REFERENCES}

[1] M. Helaimi, et al., "An Improved PIController for Resonant Inverter Induction Heating under Load and Line Variations," Studies in Informatics and Control, vol. 21, pp. 423429, 2012.

[2] V. Esteve, et al., "Improving the efficiency of IGBT series-resonant inverters using pulse density modulation," IEEE Trans. Ind. Electron., vol. 58, pp. 979-987, 2011.

[3] S. Arumugam and S. Ramareddy, "A New Method of APWM Resonant Inverter Topology for High Frequency AC Power Distribution Systems," Int. J. Advanced Networking and Applications, vol. 02, pp. 846-853, 2011.

[4] A. Belkheiri, et al., "Implementation of a Space Vector Pulse Width Modulation Technique for a Two Level Inverter,” Elektrotehniški, Vestn Ik, vol. 85, pp. 1-7, 2018.

[5] M. Helaimi, et al., "Optimal Regulator Based Control Of APWM Class-D Inverter for Induction Cooking Appication," 4th International Conference on Electrotechnics, ICEL'09, Oran, Ageria, 2009.

[6] T. Szelitzky, et al., "Complex model of a series load induction heating inverter," Acta Technica Napocensis, Electronics and Communications, vol. 52, pp. 23-27, 2011.

[7] T. K. Hassan and E. A. Ali, "Power control of series-parallel resonant inverter for induction heating using buck converter," Journal of Engineering \& Technology, vol. 28, pp. 1934-1959, 2010.

[8] J. L. Garriga and M. Soroush, "Model Predictive Control Tuning Methods: a Review," Ind. Eng. Chem. Res., vol. 49, pp. 3505-3515, 2010 .

[9] S. Vazquez, et al., "Model Predictive Control: A Review of Its Applications in Power Electronics," IEEE Industrial Electronics Magazine, vol. 8, pp. 16-31, 2014.

[10] J. F. Ardashir, et al., "A Grid Connected Transformerless Inverter and its Model Predictive Control Strategy with Leakage Current Elimination Capability," Iranian Journal of Electrical \& Electronic Engineering, vol. 13, 2017.

[11] M. Oloumi, et al., "Application of the Min-Projection and the Model Predictive Strategies for Current Control of Three-Phase Grid-Connected Converters: a Comparative Study," Iranian Journal of Electrical \& Electronic Engineering, vol. 11, 2015.

[12] A. Younesi, et al., "Improved Optimization Process for Nonlinear Model Predictive Control of PMSM," Iranian Journal of Electrical \& Electronic Engineering, vol. 14, 2018.

[13] V. R. Nakum, et al., "Research on Induction Heating-A Revie," International Journal of Science and Engineering Applications, vol. 2, 2013.

[14] S. Majid, et al., "A Simplified model of a metal disc induction heating system," HES-10, International symposium on heating by electromagnetic sources, Padua (Italy), pp. 137-144, 2010.

[15] P. Guerrier and J. H. Hattel, "Numerical modeling of magnetic induction and heating in injection molding tools," Proceedings of International Conference on Advanced Manufacturing Engineering and Technologies (NEWTECH), 2013.

[16] A. Mühlbauer, History of Induction Heating and Melting, Essen: Vulkan-Verlag GmbH, 2008.

[17] G. H. Brown, et al., Theory and Application of Radio-Frequency Heating, New York: Van Nostrand, 1947.

[18] J. W. Cable, Induction and Dielectric Heating, New York: Reinhold, 1954.

[19] V. Rudnev, et al., Handbook of induction heating, New York: Marcel Dekker Inc., 2003.

[20] J. Davies, Conduction and Induction heating, London: Peter Peregrinus Ltd., 1990.

[21] F. Forest, et al., "Frequency-synchronized resonant converters for the supply of multiwindings coils in induction cooking appliances," IEEE Transactions on Industrial Electronics, vol. 54, pp. 441-452, 2007.

[22] V. Geetha and V. Sivachidambaranathan, "An overview of designing an induction heating system for domestic applications," International Journal of Power Electronics and Drive System (IJPEDS), vol. 10, pp. 351-356, 2019.

[23] J. M. Burdío, et al., "A two-output series-resonant inverter for induction-heating cooking appliances," IEEE Transactions on Power Electronics, vol. 20, pp. 815-822, 2005.

[24] G. T. Landi and A. F. Bakuzis, "On the energy conversion efficiency in magnetic hyperthermia applications: A new perspective to analyze the departure from the linear regime," Journal of Applied Physics, vol. 111, pp. 083915-083915- 8, 2012.

[25] O. Fadli, et al., "Fault Diagnosis in Static Converters Used in Induction Heating Systems," International Journal of Power Electronics and Drive System (IJPEDS), vol. 9, pp. 1051-1063, 2018.

[26] C. C. Tai and M. K. Chen, "The design of a half-bridge series-resonant type heating system for magnetic nanoparticle thermotherapy," PIERS Online, vol. 4, pp. 276-280, 2007.

[27] C. Saichol, et al., "An Improved LLC Resonant Inverter for Induction-Heating Applications with Asymmetrical Control," IEEE Transactions on Industrial Electronics, vol. 58, pp. 2915-2925, 2011. 


\section{BIOGRAPHIES OF AUTHORS}

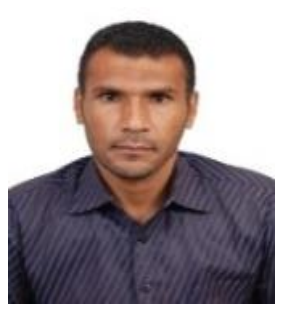

Azzedine khati received the M.SC. degree in electrical engineering in 2014 from the Hassiba Benbouali University, Chlef, Algeria, He is currently working towards his $\mathrm{Ph} . \mathrm{D}$ degree in the LGEER Laboratory (Laboratoire Génie Electrique et Energies Renouvelables). His research interest includes intelligent control strategies, electrical machine drives and robotics.

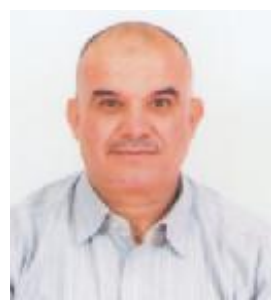

Abdelkader kansab was born in Mazouna, Algeria, in 1964. He received the doctorat degree, in Electrical Engineering from the University of Sciences and technology of Oran, Algeria, in 2008. He is currently working as an Associate Professor at the university of chlef and is a member in the LGEER Laboratory (Laboratoire Génie Electrique et Energies Renouvelables). His research interests include modeling and optimization in Electromagnetic systems and devices.



Rachid Taleb received the M.SC. degree in electrical engineering in 2004 from the Hassiba Benbouali University, Chlef, Algeria, and his the Ph.D. degree in electrical engineering in 2011 from the Djillali Liabes University, Sidi Bel-Abbes, Algeria. He is currently an Associate Professor at the Department of Electrical Engineering, Hassiba Benbouali University. He is a team leader in the LGEER Laboratory (Laboratoire Génie Electrique et Energies Renouvelables). His research interest includes intelligent control, heuristic optimization, control theory of converters and converters for renewable energy sources.



Houari Khouidmi was born in Algeria. He was post graduated from the higher teacher training school of technical teaching (ENSET), Oran, Algeria until 2006. In 2009, he joined the Sidi BelAbbès University, Algeria as a D.sc. He is currently an Associate Professor in the Department of Electronics at the Hassiba Benbouali University of Chlef. His research interests include power electronic converters, predictive control, intelligence control and the advanced control of electrical drives. 